\title{
Efficient Treatment of Sporothrix globosa Infection Using the Antibody Elicited by Recombinant Phage Nanofibers
}

\author{
Feng Chen ${ }^{1}$, Rihua Jiang ${ }^{1 *}$, Shuai Dong ${ }^{2}$ and Bailing Yan ${ }^{3 *}$ \\ ${ }^{1}$ Department of Dermatology, China-Japan Union Hospital of Jilin University, Changchun, China, ${ }^{2}$ Department \\ of Gynecology and Obstetrics, The First Hospital of Jilin University, Changchun, China, ${ }^{3}$ Department of Emergency, The First \\ Hospital of Jilin University, Changchun, China
}

OPEN ACCESS

Edited by:

Chao Wang,

The University of North Carolina at Chapel Hill, United States

Reviewed by:

Jianxun Ding,

Changchun Institute of Applied

Chemistry (CAS), China

Bailiang Wang,

Wenzhou Medical University, China

Everardo López-Romero,

Universidad de Guanajuato, Mexico

*Correspondence:

Rihua Jiang

635597795@qq.com

Bailing Yan

yanbailing@163.com

Specialty section:

This article was submitted to

Experimental Pharmacology

and Drug Discovery,

a section of the journal

Frontiers in Pharmacology

Received: 08 December 2018

Accepted: 11 February 2019

Published: 27 February 2019

Citation:

Chen $F$, Jiang $R$, Dong $S$ and

Yan B (2019) Efficient Treatment of Sporothrix globosa Infection Using the Antibody Elicited by Recombinant

Phage Nanofibers.

Front. Pharmacol. 10:160

doi: 10.3389/fphar.2019.00160
Antifungal therapy is used to treat sporotrichosis. However, there are several limitations in this therapy, such as development of drug resistance and potential health risks including liver injury. The purpose of our study was to evaluate the antifungal efficacy of antibody against the hybrid phage nanofibers displaying KPVQHALLTPLGLDR (phage$\mathrm{KR}$ ) in a fungal-infected mouse model. In this study, we extracte an antibody against hybrid phage nanofibers (phage-KR) from immunized mice and passively inoculate Sporothrix globosa ( $S$. globosa) infected mice. The study shows that the antibody exhibits efficient inhibition efficacy of the $S$. globosa infection, including reduction of the progressive fungi colonizing, increase of animal survival rate and relief of organ inflammation in the mice. The results indicate that antibody against phage-KR may act as a potential strategy for safe and efficient treatment of $S$. globosa infections.

Keywords: sporotrichosis treatment, recombinant phage nanofibers, Sporothrix globosa, antibody treatment, immune response

\section{INTRODUCTION}

Sporotrichosis is known to be an acute or chronic subcutaneous mycosis, which can affect humans and other mammals (Barros et al., 2011). Especially, the global spread of the cases of sporotrichosis tends to increase in recent years. The disease is usually categorized into four types according to clinical symptoms, including fixed cutaneous, lymphocutaneous, multifocal or disseminated, and extracutaneous (Ramos-e-Silva et al., 2007; Barros et al., 2011). It is believed that Sporothrix globosa (S. globosa) is the only pathogenic species in northeast China, despite clinical presentations or the regions where it is isolated (Yu et al., 2013).

Currently, antifungal therapy is used to treat sporotrichosis worldwide. However, there are certain limitations in this therapy. Whether administered continuously or intermittently, antifungal treatments can lead to the development of drug resistance in Sporothrix (Donnelly et al., 2008). Potential health risks associated with long-term exposure to antifungal agents may cause liver injury in asymptomatic patients, especially in patients with liver disorders, children, and pregnant women (Tuccori et al., 2008). Hence, it is crucial to find an alternative treatment for sporotrichosis, such as antibacterial materials (Lin et al., 2017; Li et al., 2018).

Gp70, a glycoprotein of $70 \mathrm{KDa}$ and a major adhesin expressed on cell surface of Sporothrix schenckii, is found to be associated with virulence of fungus (de Almeida et al., 2015; 
Rodrigues et al., 2015). It plays a key role in immunization modulation and host defense. The monoclonal antibody (mAb) against Gp70 is a candidate for vaccination against sporotrichosis, which may induce strong protection (de Almeida et al., 2015). Four peptides of Gp70 may be involved in this protection. Immunization was confirmed by mass spectrometry of digested Gp70 and the epitopes on the peptides were confirmed by using an epitope-finding algorithm.

In our previous studies, it has been found that recombinant phage displaying peptide KPVQHALLTPLGLDR (KR, one of the four peptides) could enhance the immune responses of $\mathrm{T}$ helper (Th) 1 and Th17 cells and elicit antibody against $\mathrm{Gp} 70$ in $\mathrm{BALB} / \mathrm{c}$ mice, leading to the inhibition of subsequent infection of the mice (Chen et al., 2017). Phage displaying other three peptides cannot elicit efficient protective immune response. So, in this study, only the antibody against hybrid phage displaying KPVQHALLTPLGLDR (phage-KR) was extracted from the immunized mice and then passively inoculated into $S$. globosa-infected mice. The curing efficacies of the treatment including anti-fungal effects, alleviation of inflammation of the organs and improvement of animal survival rate by the treatment were evaluated (Scheme 1).

\section{MATERIALS AND METHODS}

\section{Animals}

BALB/c mice (6-8 weeks of age, $20-25$ g body weight) were received from Beijing HuaFuKang Biological Technology Co., Ltd. (China). An animal facility with specific pathogen-free conditions was used to raise the mice. All animal procedures in this study were performed in accordance with the Guidelines for Care and Use of Laboratory Animals of Jilin University and approved by the Animal Ethics Committee of The First Hospital of Jilin University (Protocol No. 2017-096-01).

\section{Strain and Culture Conditions}

This study was carried out in accordance with the recommendations of Guidelines for Use of Patient Specimens, Ethics Committee of China-Japan Union Hospital of Jilin University. The protocol was approved by the Ethics Committee of China-Japan Union Hospital of Jilin University. All subjects gave written informed consent in accordance with the Declaration of Helsinki. Cultured isolates were obtained from the patients who were diagnosed with invasive sporotrichosis. Sequence searches in GenBank revealed that all isolates were $S$. globosa strains. The isolates were allowed to grow on Sabouraud dextrose agar slants at $28{ }^{\circ} \mathrm{C}$ for 7 days. Fungus was then added to brain heart infusion (BHI) broth and cultured at $37^{\circ} \mathrm{C}$ for 7 days. The conidia taken from the cultures were diluted to $1 \times 10^{8}$ cells $/ \mathrm{mL}$ (Lyon et al., 2013; Nunes Mario et al., 2014). The yeast cells were heat-killed for $2 \mathrm{~h}$ at $60^{\circ} \mathrm{C}$. The heat-killed S. globosa (HK-SP) were conserved at $4^{\circ} \mathrm{C}$ (Tachibana et al., 1999).

\section{Phages}

The sequence of peptide KR was displayed on the gene III of f388-55 phage vector previously. Phage expressing peptide KR could elicit antibody against $S$. globosa and induce a mixed Th1/Th17 response (Supplementary Figure S1). Wild type phages were produced as described previously and conserved in our laboratory (Wang et al., 2014). The phage pellet was allowed to resuspend in PBS.

\section{SDS-PAGE}

Expression of peptide KR by recombinant phage was tested by sodium dodecyl sulfate polyacrylamide gel electrophoresis (SDSPAGE). The samples of phage were boiled for $10 \mathrm{~min}$ in an equal volume of $2 \times$ sample loading buffer containing $100 \mathrm{mM}$ Tris$\mathrm{HCl}$ (pH 8.3), 4\% SDS, 20\% glycerol, and $0.02 \%$ bromophenol blue. Proteins were then electrophoresed. The protein bands were shown by silver-staining according to the procedure by Schagger and von Jagow (1987).

\section{Production of Antibodies}

The BALB/c mice were randomly divided into four groups. At a weekly interval, the BALB/c mice were injected intraperitoneally for immunization for four times with different formulations, including $100 \mu \mathrm{l}$ of PBS containing $25 \mu \mathrm{g}$ phage-KR nanofibers (denoted as group RP), $100 \mu \mathrm{l}$ of PBS with $25 \mu \mathrm{g}$ wild-type phage nanofibers (denoted as group Mock), $100 \mu \mathrm{l}$ of PBS with $10^{8}$ HK-SP (denoted as group HK-SP), or PBS only as the negative control (denoted as group PBS). One week after the last immunization, sera were collected from the immunized mice, and IgG antibody was extracted and purified from the sera based on the manufacturer's procedure by using HiTrap Protein G HP column (a product of GE General Electric, United States).

\section{Western Blotting}

The serum collected from the mice with disseminated sporotrichosis containing antibodies against Gp70 of S. globosa or control individuals (de Almeida et al., 2015). The protein was denatured, electrophoresed, and transblotted onto a nitrocellulose membrane in Tris/Glycine buffer. The membrane was blocked in TBS-T with $5 \%(\mathrm{w} / \mathrm{v})$ non-fat milk at $4^{\circ} \mathrm{C}$ overnight. Following washing with TBS-T for four times, the nitrocellulose membrane was cultured in a 1:80 dilution of serum in TBST with $5 \%$ non-fat milk at $37^{\circ} \mathrm{C}$ for $1 \mathrm{~h}$. Following washing, the membrane was further cultured at $37^{\circ} \mathrm{C}$ with goat antimouse IgG conjugated with peroxidase (obtained from Vector Laboratories Inc., of United States) for $1 \mathrm{~h}$, and then stained with 3-amino-9-ethylcarbozole (AEC) for acting as a chromogen.

\section{Immunofluorescence}

$1 \times 108$ sporophores were cultured in 6-well tissue culture plates with RPMI 1640 medium for $4 \mathrm{~h}$. Following slight washing using PBS, the cells were cultured with the sera containing antibodies against recombinant phage displaying peptide KR (RP) or wild type phage (Mock) for $2 \mathrm{~h}$ on ice. The adherent cells were fixed using $4 \%$ paraformaldehyde for $20 \mathrm{~min}$, followed by washing with PBS three times. The cells were then permeabilized with 


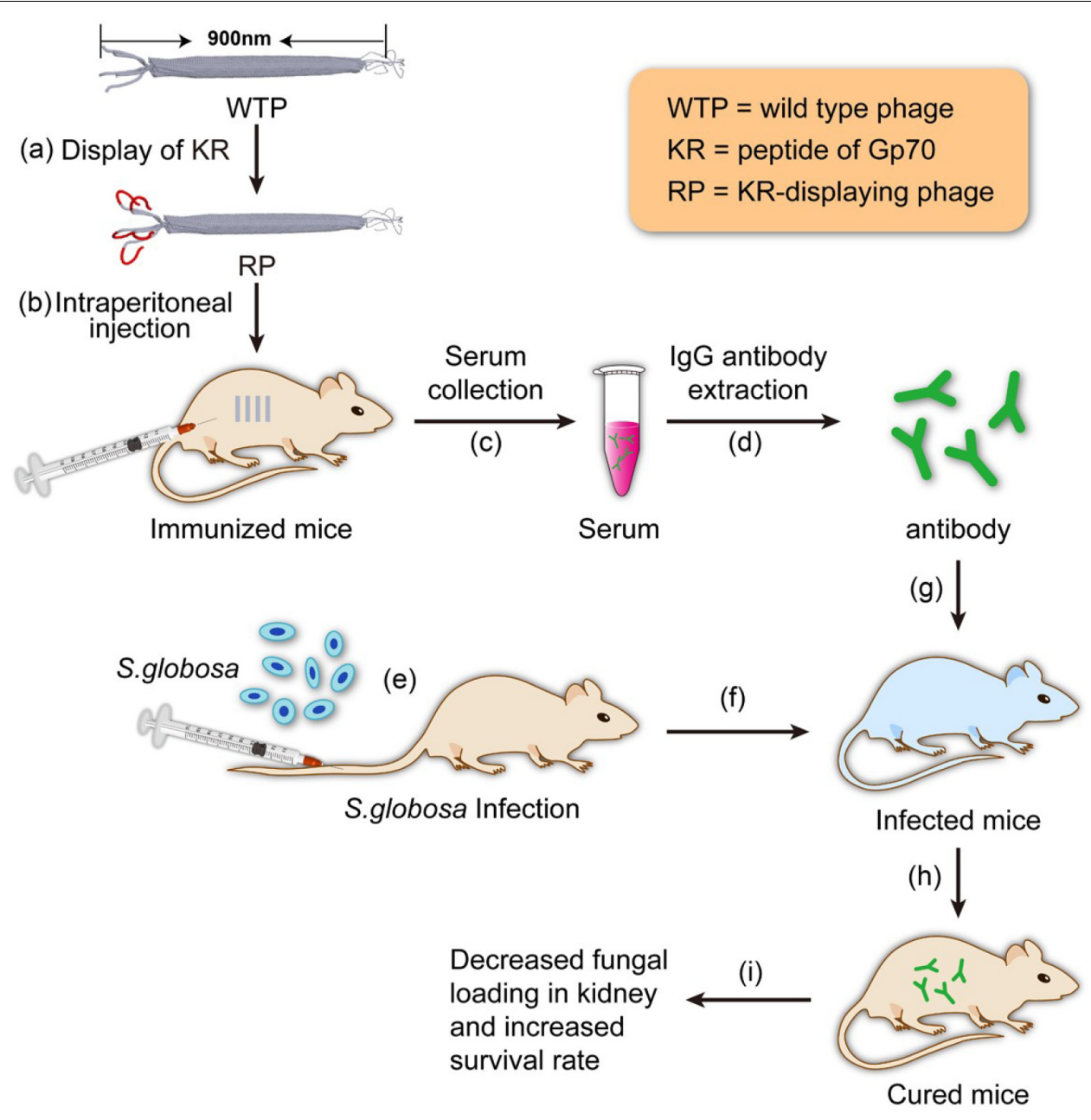

SCHEME 1 | Schematic illustration of using the antibody elicited by RP nanofibers ( 900 nm long and $\sim 7 \mathrm{~nm}$ wide) for treating Sporothrix globosa infection.

$0.5 \%$ Triton X-100, followed by further washing with TBST three times. After blocking with $3 \%$ bovine serum albumin (BSA) at $37^{\circ} \mathrm{C}$, the cells were cultured with a $1: 1000$ dilution of antiphage g3p (pIII) antibody in PBS buffer $\left(\mathrm{pH} \mathrm{7.4)}\right.$ at $4^{\circ} \mathrm{C}$ for $1 \mathrm{~h}$, followed by incubation with $\mathrm{Cy} 3$ labeled goat-anti-mouse IgG (1:2000) (Abbkine, United States) for another $45 \mathrm{~min}$ at $37^{\circ} \mathrm{C}$ and staining by $4^{\prime}, 6$-diamidino-2-phenylindole (DAPI) for $10 \mathrm{~min}$. With washing by PBS containing $0.1 \%$ Tween 20 for three times, the cells were viewed by a laser scanning confocal microscope.

\section{Treating S. globosa With Antibodies Against Sporotrichosis}

The mouse model infected with disseminated S. globosa was established by intravenous injection of $0.2 \mathrm{ml}\left(1 \times 10^{8}\right.$ cells $\left./ \mathrm{ml}\right)$ of $S$. globosa suspension, then the mice were randomly divided into four groups ( $n=6$ per group). One day after infection, mice were intravenously given the following antibodies once every 3 days for a total of three administrations: (1) purified antibody against phage-KR (100 $\mu \mathrm{L})$; (2) purified antibody against wild-type phage $(100 \mu \mathrm{L})$; (3) purified antibody against HK-SP (100 $\mu \mathrm{L})$; and (4)
$100 \mu \mathrm{L}$ PBS. All dosages were $5 \mathrm{mg}$ per kg body weight. Finally, the mice were sacrificed 2 weeks after the final infection.

\section{Assessment of Protection}

To evaluate the colony forming units (CFU) of S. globosa at a unit of per gram of tissue, all the kidneys were excised from the mice under aseptic condition ( $n=6$ in each group). The kidneys were weighed and then homogenized in $3 \mathrm{ml}$ of sterile saline by using the glass tissue homogenizers. After that, saline was used to dilute the tissue homogenate, which was then put up on Sabouraud's dextrose agar. Additionally, for the histological analysis, the kidneys of the mice were removed and fixed with formalin [10\% $(\mathrm{v} / \mathrm{v})]$. The buffered paraffin-embedded tissues were sectioned into slices with $3 \sim 5 \mu \mathrm{m}$ thickness for hematoxylin and eosin (H\&E) staining.

To evaluate the survival time of the mice, the mouse model infected with disseminated $S$. globosa was established by intravenous injection of $0.2 \mathrm{ml}\left(5 \times 10^{8}\right.$ cells $\left./ \mathrm{ml}\right)$ of $S$. globosa suspension, and the mice were separated into four groups ( $n=10$ per group). One day post infection the mice were given 
A

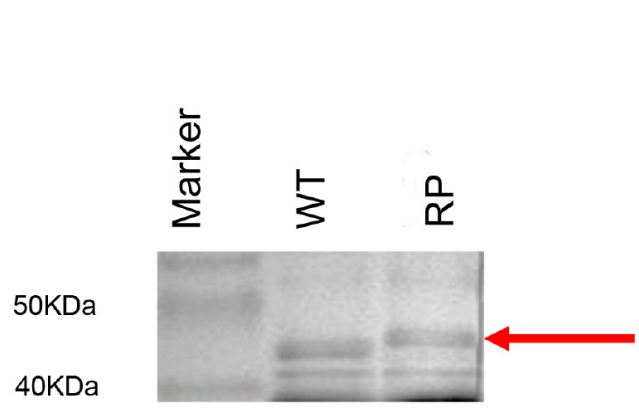

B

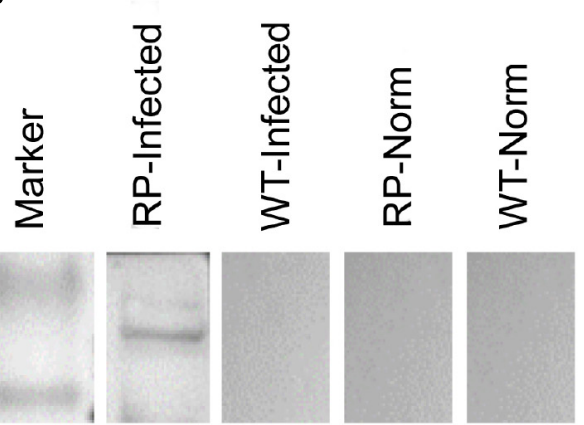

FIGURE 1 | Expression and antigenicity of phage-displayed peptide. (A) SDS-PAGE (20\%) of wild-type phage (WT) (46 kDa) and recombinant phage (RP) displaying peptide KPVQHALLTPLGLDR. (B) Western blot of RP and WT phage with the serum of infected mouse containing an antibody to a $70 \mathrm{kDa}$ protein band, or with the serum of the control individual: Lane 1: Marker; Lane 2: RP phage probed with the serum of infected mouse; Lane 3: WT phage probed with the serum of infected mouse; Lane 4: RP phage with normal serum; Lane 5: WT phage with normal serum.

antibodies intravenously as described above. The survival time was monitored for 2 weeks following treatment.

\section{Assessment of Liver and Renal Injury}

Toxicity was assessed 1 day after passive therapy. Blood samples (50 $\mu \mathrm{l}$ in each mouse) were obtained through the lateral tail vein, followed by transferring into $0.5 \mathrm{~mL}$ centrifugation tubes. For each sample, clinical biochemistry parameters were measured by ELISA diagnostic kits (Rongsheng, Shanghai, China; Yutong, Jiangsu, China, respectively) (Chen et al., 2017).

\section{Statistical Analysis}

We examined the differences in the survival time between different groups by the Log-rank test. Analysis of Variance was used for analysis of the data. The criterion for statistical significance was $p<0.05$.

\section{RESULTS}

\section{Production of Recombinant Phage}

Expression of phage-KR was evaluated by using SDS-PAGE (Figure 1A). Sera collected from mice infected with systematic sporotrichosis reacted with the fusion protein band in hybrid phage (Figure 1B). The results indicated that the hybrid recombinant phage displayed the peptide KR on the surface.

\section{Antibody Response Against Phage Displaying Peptide KR in Immunized Mice}

Our results showed that immunization with the hybrid phage expressing peptide KPVQHALLTPLGLDR (phage-KR) produced antibodies in the sera, which is able to bind Gp70 (Figure 2). By immunofluorescence assay, we demonstrated that the antibodies could also recognize Gp70 expressed by S. globosa (Figure 3). Hence, the results showed that the recombinant phage displaying peptide KR could exhibit similar function to Gp70 for treatment of S. globosa infection collectively. Namely, the peptide KR

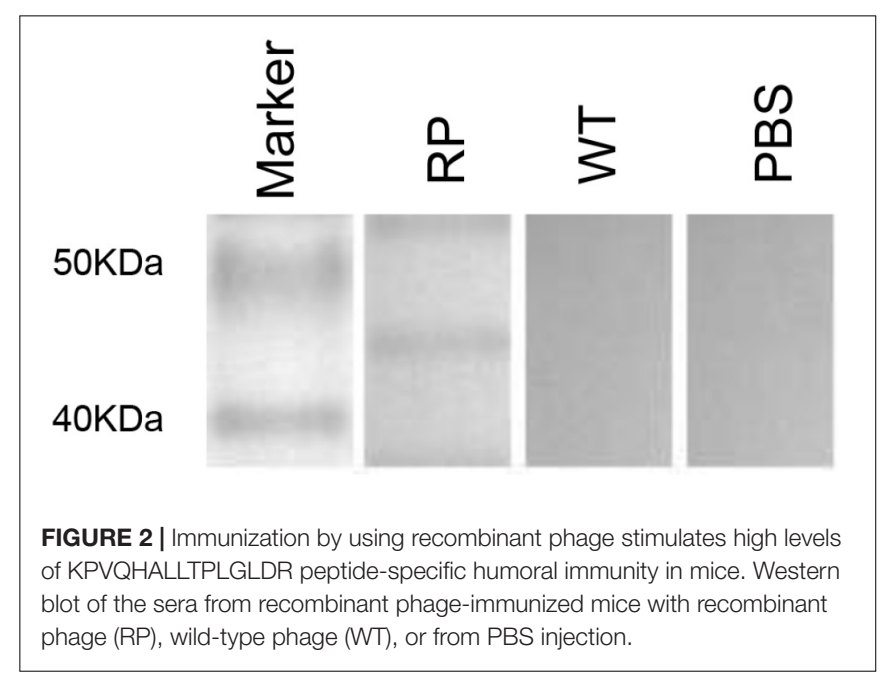

expressed on the surface of the phage is able to mimic Gp70, a cell surface component, and induce the mice to generate antibodies which can bind to Gp70 for treatment of the infection.

\section{Assessment of Using Antibody Against Recombinant Phage to Protect Systemic S. globosa Infection}

To assess the feasibility of using antibody against Gp70 (antiGp70) IgG to treat sporotrichosis, IgG was collected and purified from the sera of the immunized mice, followed by administrating to the mice that were infected with S. globosa at a lethal dose $\left(1 \times 10^{8}\right.$ cells $)$. The survival time of the mice was monitored over 14 days (Figure 4). It was found that the group injected with antibody against phage-KR exhibited the highest survival rate $(80 \%)$. In contrast, the mice treated with PBS showed a much lower survival rate of only $30 \%$. For the group treated with antibody against HK-SP, an increased survival rate (70\%) was also found at 14 days following infection. Significantly enhanced survival rate was obtained in the mice treated with antibody against phage-KR compared to the PBS-treated mice. The CFUs 


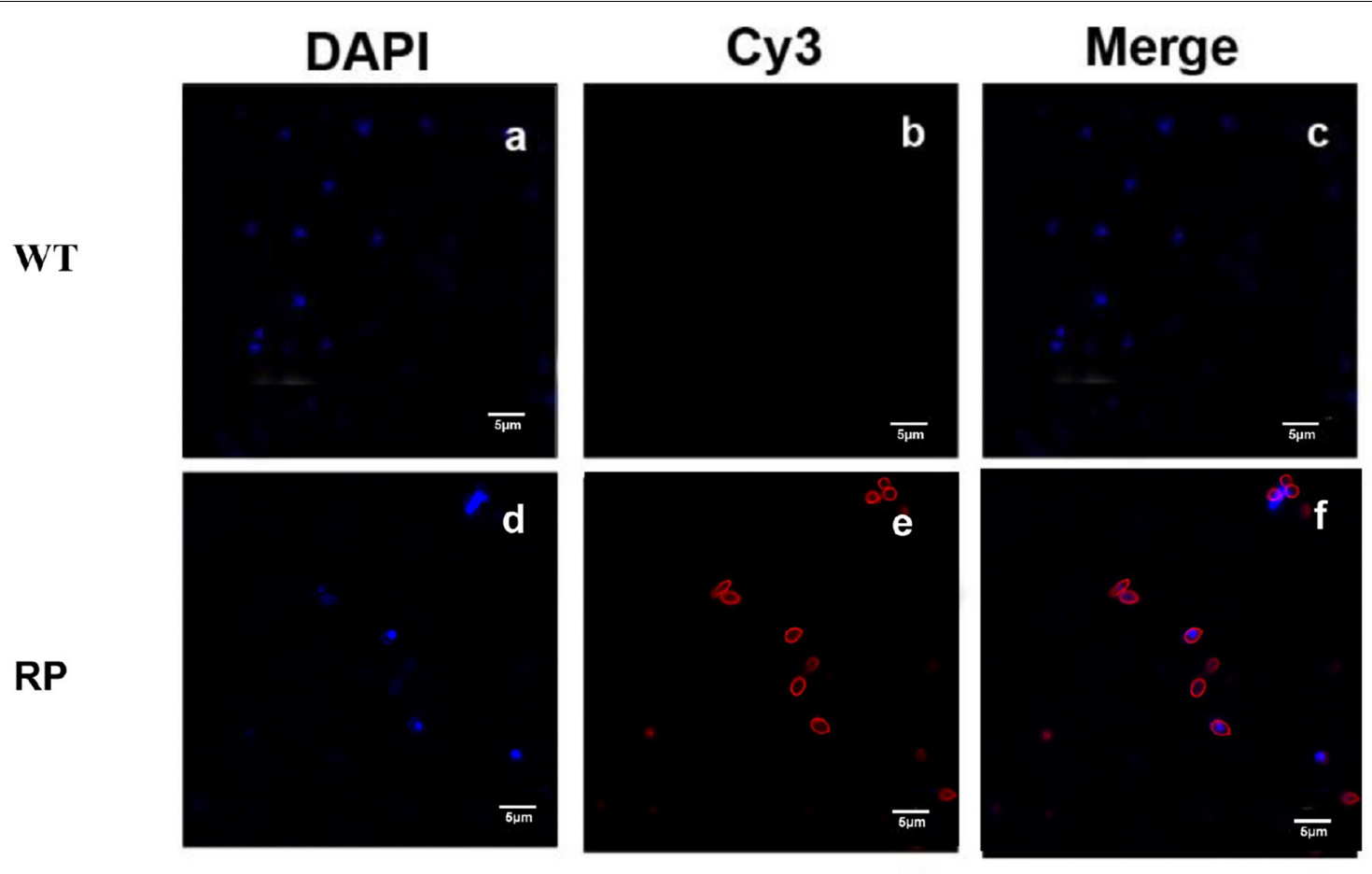

FIGURE 3 | Immunofluorescence to evaluate the binding affinity between the antibody containing sera and S. globosa. (a) S. globosa stained by DAPI (excitation: $358 \mathrm{~nm}$, emission: $461 \mathrm{~nm}$ ); (b) S. globosa incubated with the sera containing anti-RP (recombinant phage displaying peptide (KPVQHALLTPLGLDR), followed by staining by Cy3-conjugated goat anti-mouse lgG (excitation: 495 nm, emission: 519 nm); (c) Merged picture of image (a) and image (b); (d) S. globosa stained by DAPI (excitation: $358 \mathrm{~nm}$, emission: $461 \mathrm{~nm}$ ); (e) S. globosa incubated with anti-WP containing sera, followed by staining with Cy3-conjugated goat anti-mouse IgG (excitation: $550 \mathrm{~nm}$, emission: $570 \mathrm{~nm}$ ); (f) merged picture of image (d) and image (e). Recombinant phage (RP); Wild-type phage (WT).

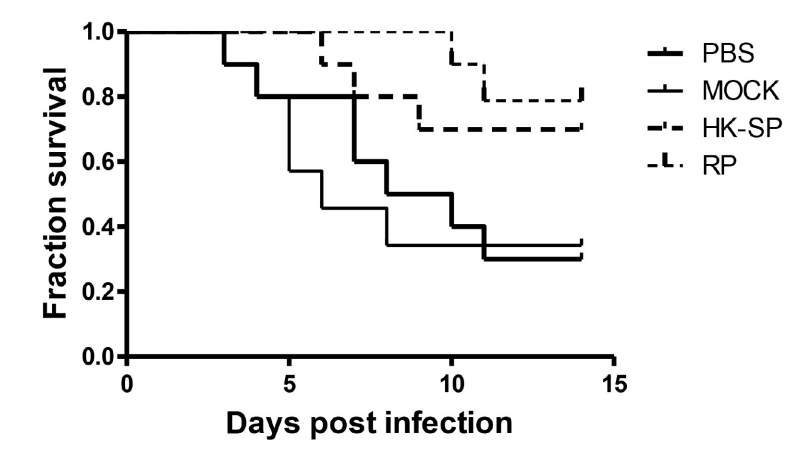

FIGURE 4 | Survival rate of the S. globosa infected mice treated with purified antibodies against recombinant phage (RP), wild-type phage (MOCK), or heat-killed Sporothrix globosa (HK-SP), or with PBS alone. The mice were intravenously treated once every 3 days for a total of three administrations. All dosages were $5 \mathrm{mg}$ per $\mathrm{kg}$ body weight. The group treated with RP vs. PBS-treated group, ${ }^{*} P=0.01$; The group treated with HK-SP vs. PBS treated group, $P=0.04$; Wild-type phage treated group vs. PBS treated group, $P=0.79$.

in the kidneys of the animals immunized with antibody against phage-KR or antibody against HK-SP were statistically decreased, compared to the mice treated with antibody against wild-type phage or PBS injected mice (Figure 5). The histopathological changes between these groups were consistent with the results of the survival study. Macroscopically, there were no lesions observed in internal organs. However, extensive lymphocytes and neutrophils were observed in the kidney of the group MOCK and group PBS by H\&E staining, clearly indicating inflammation. In contrast, only medium levels of lymphocytes and neutrophils were observed in the kidney of the group treated with antibody against phage-KR or antibody against HK-SP (Figure 6).

\section{Liver and Renal Function}

The toxicological assessment of the treatments was carried out. Clinical biochemistry parameters, including aspartate aminotransferase, alanine aminotransferase, alkaline phosphatase, glucose, urea, creatinine, total protein, and albumin, indicated values in normal biological ranges. No obvious difference between the treated groups and control group was observed.

\section{DISCUSSION}

Sporotrichosis is currently distributed throughout the world with a significant increase in human and animal cases over the last two decades. By far, considerable efforts have been made to develop vaccines for human infections caused by Sporothrix species. We have previously demonstrated that phage displaying KR could 
elicit protective immunity against fungal diseases (Chen et al., 2017). In this study, the potential treatment efficacy of antiphage-KR IgG against Sporotrichosis was explored. We show that anti-HK-SP or anti-phage-KR antibody can reduce the extent of the damage and improve the survival rate of the mice infected with S. globosa.

Sporotrichosis is a subcutaneous mycosis resulted from the S. schenckii complex, and routine antifungal drugs are not suitable for all patients. Nascimento et al. (2008) demonstrated that the Gp70 molecule is a putative adhesin for fibronectin and laminin, as well as anti-Gp70. Additionally, the yeast cells opsonized with anti-Gp70 mAb increase the phagocytic index (de Almeida et al.,

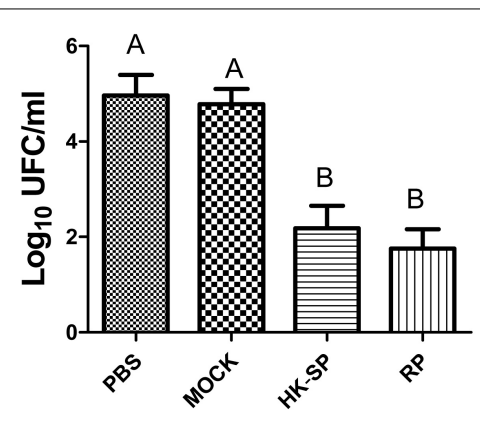

FIGURE 5 | Log CFU/g in the kidneys of the mice. After the mice were sacrificed, and Log CFU/g were quantified 15 days following the immunization. Significantly less CFU in the kidneys of hybrid phage-treated mice was observed than in those treated with wild-type phage (MOCK) and PBS (control). No statistically significant difference between the group treated with HK-SP and that treated with recombinant phage (RP). Values followed by different capital letters differ significantly among the PBS, MOCK, HK-SP, and RP groups.
2015). The immunity inhibits interaction between S. schenckii yeast cells and the subendothelial matrix.

The humoral immune response appears to prevent and control sporotrichosis infection in mice. Antibodies play an important role in protecting the host from fungal infections, including the agglutination of fungal cells, impeding of fungal attachment, increase of the phagocytosis by host effector cells, neutralizing of immunoregulatory molecules, as well as the complement activation (Nascimento et al., 2008). The incapacity of immune sera to mediate protection from fungi indicates insufficient amounts of protective antibody instead of a fundamental incapability of antibodies in protecting against fungal pathogens. However, phage nanofibers could display peptide KR on the surface through genetic means, allowing the peptide $\mathrm{KR}$ to possess a conformation analogical to the native protein. Furthermore, they have the ability to induce the antibody response. Additional benefits include the easiness of production and cost-effectiveness, as well as nontoxicity to humans.

The immunogenicity of epitopes is increased when they are expressed on the phage. Mice sera raised against hybrid phage reacted with peptide KR (Figure 2), suggesting that the specific response of antibody to the hybrid phage may be motivated by peptide KR instead of the components of phage. Antibodies are naturally generated products of the immune system that interact with other immune components. Additionally, protective antibodies may act through the complement-mediated lysis, promotion of phagocytosis, as well as Fc-mediated release of cytokine and direct antimicrobial efficiency (Casadevall et al., 2004). Furthermore, IgG was collocted and purified from the sera of the immunized mice, and then administered into the mice infected with $S$. globosa, leading to significant reduction of the
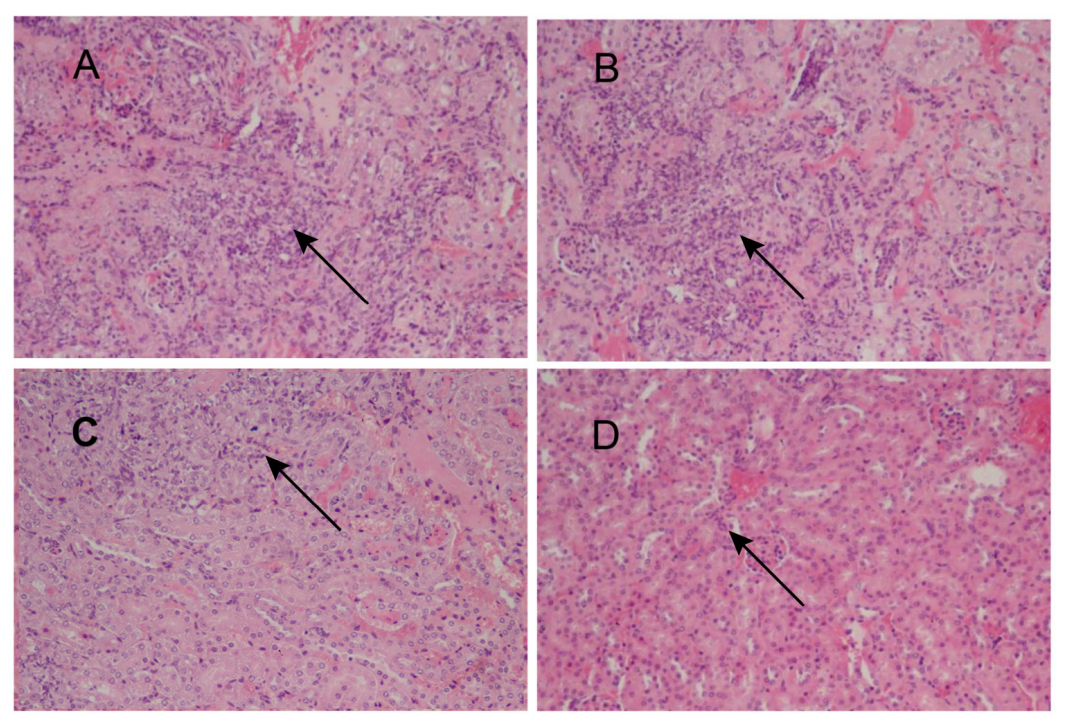

FIGURE 6 | Images of H\&E-stained kidney of the S. globosa-infected mouse treated with various formulations, Magnification $200 \times$. (A) PBS injection (B) antibody against wild-type phage injection (C) antibody against HK-SP injection (D) Antibody against phage-KR injection. (A,B) Showed a higher number of inflammatory cells. In contrast (C,D) show a dramatic decrease in neutrophil and lymphocyte infiltration. The arrows indicate infiltration of inflammatory cells. 
number of $\mathrm{CFU}$ and decreased accumulation of inflammatory cells in the kidney. Moreover, injection of IgG significantly enhanced the survival rate of mice infected with S. globosa. Our study demonstrates that the antibody against $S$. globosa elicited by phage-KR can efficiently protect the mice from disseminated infection of $S$. globosa. Further studies should examine the protection of phage-KR in other Sporothrix strains.

Itraconazole-resistant strains of $S$. schenckii complex have been reported (Oliveira et al., 2011; Ottonelli Stopiglia et al., 2014). The use of phage-KR without adjuvant may lead to significant improvement in the efficacy of antifungal therapy, as well as a reduced inflammation reaction. This approach may avoid the adverse side effects of the antifungal drug, especially for the patients with liver dysfunction, pregnant women, and children, who are not suitable for antifungal drug therapy (Kauffman et al., 2000). It is worth mentioning, although the mechanism for phage responses still remains unknown, no obvious adverse effects of phage have been detected in considerable preclinical studies carried out in various animal models. Although phage-KR would not replace conventional antifungal agents, we show that phage-KR may be an important alternative to existing therapies in some cases (Almeida-Paes et al., 2007).

\section{CONCLUSION}

In conclusion, this study shows clearly the therapeutic efficiency of the humoral immune response generated by recombinant phage for the treatment of S. globosa infection in a fungal infected mouse model. It is notable that the antibody elicited by phage-KR

\section{REFERENCES}

Almeida-Paes, R., Pimenta, M. A., Monteiro, P. C., Nosanchuk, J. D., and Zancope-Oliveira, R. M. (2007). Immunoglobulins G, M, and A against Sporothrix schenckii exoantigens in patients with sporotrichosis before and during treatment with itraconazole. Clin. Vaccine Immunol. 14, 1149-1157. doi: 10.1128/CVI.00149-07

Barros, M. B., de Almeida Paes, R., and Schubach, A. O. (2011). Sporothrix schenckii and Sporotrichosis. Clin. Microbiol. Rev. 24, 633-654. doi: 10.1128/CMR.000 07-11

Casadevall, A., Dadachova, E., and Pirofski, L. A. (2004). Passive antibody therapy for infectious diseases. Nat. Rev. Microbiol. 2, 695-703. doi: 10.1038/nrmicro974

Chen, F., Jiang, R., Wang, Y., Zhu, M., Zhang, X., Dong, S., et al. (2017). Recombinant phage elicits protective immune response against systemic $\mathrm{S}$. globosa infection in mouse model. Sci. Rep. 7:42024. doi: 10.1038/srep42024

de Almeida, J. R., Kaihami, G. H., Jannuzzi, G. P., and de Almeida, S. R. (2015). Therapeutic vaccine using a monoclonal antibody against a $70-\mathrm{kDa}$ glycoprotein in mice infected with highly virulent Sporothrix schenckii and Sporothrix brasiliensis. Med. Mycol. 53, 42-50. doi: 10.1093/mmy/myu049

Donnelly, R. F., McCarron, P. A., and Tunney, M. M. (2008). Antifungal photodynamic therapy. Microbiol. Res. 163, 1-12. doi: 10.1016/j.micres.2007. 08.001

Kauffman, C. A., Hajjeh, R., and Chapman, S. W. (2000). Practice guidelines for the management of patients with sporotrichosis. For the mycoses study group. Infectious diseases society of America. Clin. Infect. Dis. 30, 684-687. doi: $10.1086 / 313751$

Li, S., Dong, S., Xu, W., Tu, S., Yan, L., Zhao, C., et al. (2018). Antibacterial hydrogels. Adv. Sci. 5:1700527. doi: 10.1002/advs.201700527 nanofibers displays efficient inhibition of the infection, such as decrease of the progressive fungi colonizing, alleviation of kidney inflammation and reduction of the mortality rate of the mice with sporotrichosis. Overall, the strategy of using antibody against phage-KR can be an efficient and safe approach for the treatment of sporotrichosis infection.

\section{DATA AVAILABILITY}

All datasets generated for this study are included in the manuscript and/or the Supplementary Files.

\section{AUTHOR CONTRIBUTIONS}

FC, BY, and RJ conceived and designed the experiments and analyzed the data. FC and SD performed the experiments. FC and BY wrote the manuscript.

\section{FUNDING}

This work was supported by the Department of Science and Technology of Jilin Province (\#20180414033GH).

\section{SUPPLEMENTARY MATERIAL}

The Supplementary Material for this article can be found online at: https://www.frontiersin.org/articles/10.3389/fphar. 2019.00160/full\#supplementary-material

Lin, J., Ding, J., Dai, Y., Wang, X., Wei, J., and Chen, Y. (2017). Antibacterial zinc oxide hybrid with gelatin coating. Mater. Sci. Eng. C 81, 321-326. doi: 10.1016/j.msec.2017.08.009

Lyon, J. P., Moreira, L. M., de Carvalho, V. S., dos Santos, F. V., de Lima, C. J., and de Resende, M. A. (2013). In vitro photodynamic therapy against Foncecaea pedrosoi and Cladophialophora carrionii. Mycoses 56, 157-161. doi: 10.1111/j. 1439-0507.2012.02226.x

Nascimento, R. C., Espindola, N. M., Castro, R. A., Teixeira, P. A., Loureiro y Penha, C. V., Lopes-Bezerra, L. M., et al. (2008). Passive immunization with monoclonal antibody against a $70-\mathrm{kDa}$ putative adhesin of Sporothrix schenckii induces protection in murine sporotrichosis. Eur. J. Immunol. 38, 3080-3089. doi: 10.1002/eji.200838513

Nunes Mario, D. A., Denardi, L. B., Brayer Pereira, D. I., Santurio, J. M., and Alves, S. H. (2014). In vitro photodynamic inactivation of Sporothrix schenckii complex species. Med. Mycol. 52, 770-773. doi: 10.1093/mmy/myu041

Oliveira, D. C., Lopes, P. G., Spader, T. B., Mahl, C. D., Tronco-Alves, G. R., Lara, V. M., et al. (2011). Antifungal susceptibilities of Sporothrix albicans, S. brasiliensis, and S. luriei of the S. schenckii complex identified in Brazil. J. Clin. Microbiol. 49, 3047-3049. doi: 10.1128/JCM.00255-11

Ottonelli Stopiglia, C. D., Magagnin, C. M., Castrillon, M. R., Mendes, S. D., Heidrich, D., Valente, P., et al. (2014). Antifungal susceptibilities and identification of species of the Sporothrix schenckii complex isolated in Brazil. Med. Mycol. 52, 56-64. doi: 10.3109/13693786.2013.818726

Ramos-e-Silva, M., Vasconcelos, C., Carneiro, S., and Cestari, T. (2007). Sporotrichosis. Clin. Dermatol. 25, 181-187. doi: 10.1016/j.clindermatol.2006. 05.006

Rodrigues, A. M., Fernandes, G. F., Araujo, L. M., Della Terra, P. P., dos Santos, P. O., Pereira, S. A., et al. (2015). Proteomics-based characterization of the 
humoral immune response in sporotrichosis: toward discovery of potential diagnostic and vaccine antigens. PLoS Negl. Trop. Dis. 9:e0004016. doi: 10.1371/ journal.pntd.0004016

Schagger, H., and von Jagow, G. (1987). Tricine-sodium dodecyl sulfatepolyacrylamide gel electrophoresis for the separation of proteins in the range from 1 to $100 \mathrm{kDa}$. Anal. Biochem. 166, 368-379. doi: 10.1016/0003-2697(87) 90587-2

Tachibana, T., Matsuyama, T., and Mitsuyama, M. (1999). Involvement of CD4+ T cells and macrophages in acquired protection against infection with Sporothrix schenckii in mice. Med. Mycol. 37, 397-404. doi: 10.1046/j.1365-280X.1999. 00239.x

Tuccori, M., Bresci, F., Guidi, B., Blandizzi, C., Del Tacca, M., and Di Paolo, M. (2008). Fatal hepatitis after long-term pulse itraconazole treatment for onychomycosis. Ann. Pharmacother. 42, 1112-1117. doi: 10.1345/aph. $1 \mathrm{~L} 051$

Wang, Y., Su, Q., Dong, S., Shi, H., Gao, X., and Wang, L. (2014). Hybrid phage displaying SLAQVKYTSASSI induces protection against Candida albicans challenge in BALB/c mice. Hum. Vaccine Immunother. 10, 1057-1063. doi: 10.4161/hv.27714

Yu, X., Wan, Z., Zhang, Z., Li, F., Li, R., and Liu, X. (2013). Phenotypic and molecular identification of Sporothrix isolates of clinical origin in Northeast China. Mycopathologia 176, 67-74. doi: 10.1007/s11046-0139668-6

Conflict of Interest Statement: The authors declare that the research was conducted in the absence of any commercial or financial relationships that could be construed as a potential conflict of interest.

Copyright (c) 2019 Chen, Jiang, Dong and Yan. This is an open-access article distributed under the terms of the Creative Commons Attribution License (CC BY). The use, distribution or reproduction in other forums is permitted, provided the original author(s) and the copyright owner(s) are credited and that the original publication in this journal is cited, in accordance with accepted academic practice. No use, distribution or reproduction is permitted which does not comply with these terms. 